\title{
The use of aminated cotton fibers as an unconventional sorbent to remove anionic dyes from aqueous solutions
}

\author{
Tomasz Jóźwiak (D) Urszula Filipkowska • Szczepan Brym • Malwina Zyśk
}

Received: 20 August 2019/Accepted: 12 February 2020/Published online: 18 February 2020

(C) The Author(s) 2020

\begin{abstract}
This study aimed to investigate the sorption of anionic dyes (Reactive Black 5, Reactive Yellow 84, Acid Red 18, and Acid Yellow 23) by cotton fibers aminated with epichlorohydrin and ammonia water (ACFs) as well by unmodified cotton fibers (CFs). CFs and ACFs were characterized based on FTIR, elemental analysis $(\mathrm{C} / \mathrm{N}$ content $)$ and $\mathrm{pH}_{\mathrm{PZC}}$. The effect of solution $\mathrm{pH}(\mathrm{pH} 2-11)$ and contact time on the removal of dye was studied as well. The kinetic experimental data were fitted to pseudo-first order, pseudo-second order, and intraparticle diffusion model. Equilibrium isotherms were analyzed based on Langmuir and Freundlich isotherms. The efficiency of dye sorption on CFs was the most effective at $\mathrm{pH} 2$, whereas on ACFs - at pH 3-4. ACFs and CFs changed the $\mathrm{pH}$ value of the sorption solution. The system
\end{abstract}

T. Jóźwiak $(\bowtie) \cdot$ U. Filipkowska · M. Zyśk

Department of Environmental Engineering, University of Warmia and Mazury in Olsztyn, ul. Warszawska 117a, 10-957 Olsztyn, Poland

e-mail: tomasz.jozwiak@uwm.edu.pl

U. Filipkowska

e-mail: urszula.filipkowska@uwm.edu.pl

M. Zyśk

e-mail: malwina@vp.pl

S. Brym

Chair of Relativistic Physics, University of Warmia and Mazury in Olsztyn, ul. Słoneczna 54, 10-710 Olsztyn,

Poland

e-mail: szbrym@matman.uwm.edu.pl tended to obtain a $\mathrm{pH}$ value close to the $\mathrm{pH}_{\mathrm{PZC}}$ value of the sorbent $\left(\mathrm{pH}_{\mathrm{PZC}}=7.85\right.$ for $\mathrm{CFs} / \mathrm{pH}_{\mathrm{PZC}}=8.15$ for ACFs). ACFs had a shorter dye sorption equilibrium time compared to the CFs. The sorption of dyes on cotton sorbents proceeded in 2 main phases. The best match to the experimental data was shown by the pseudo-secondary model. Having amine functional groups, the ACFs ensured far better sorption of anionic dyes than CFs did. The maximum Reactive Black 5 sorption capacity of ACFs was $\mathrm{Q}_{\max }=36.77 \mathrm{mg} / \mathrm{g}$, which was $1240 \%$ higher than that of $C F s\left(Q_{\max }\right.$ $=2.74 \mathrm{mg} / \mathrm{g}$ ).

Keywords Cotton fibers - Sorption - Amination · Unconventional sorbents · Anionic dyes

\section{Introduction}

About 1 million tons of dyes are produced annually for the textile, tanning, and paper industries, with anionic dyes accounting for over $30 \%$ of the total (Wawrzkiewicz et al. 2017). They are popular due to the highly intense color and convenience of application. Their drawback, however, is their high solubility in water, which increases dye loss during dyeing. Up to $50 \%$ of the dye used in the dyeing process may enter the postproduction waters (Toosi et al. 2017). 
Colored industrial wastewater is particularly troublesome. Due to the presence of aromatic rings, dyes are hardly biodegradable, which results in a low efficiency of colored wastewater treatment with conventional methods like the biological ones based on the technology of activated sludge or biological membrane (Xiao et al. 2018).

It is currently believed that adsorption, i.e. the binding of contaminants on the surface of a sorbent, represents one of the most effective and the most environmental-friendly methods for sewage decolorization (Zhang et al. 2019; Farooq et al. 2019). Among commercial sorbents, the most popular are based on activated carbons. They have a very large surface area (more than $1000 \mathrm{~m}^{2} / \mathrm{g}$ ) (Hina et al. 2018) and exhibit good sorption properties against most types of dyes (Joshi et al. 2019), but are very expensive. Therefore, a search for cheaper and more efficient substitutes for activated carbons is underway today.

Chitosan, i.e. a chitin derivative obtained from the shells of marine crustaceans (mainly shrimps, crabs), has proved to be a good alternative to the commercial activated carbons (Filipkowska et al. 2017). Sorbents based on chitosan can exhibit much better sorption properties than the activated carbons do. In the case of anionic dyes, its maximum sorption capacity may reach $Q_{\max }=1500-2500 \mathrm{mg} / \mathrm{g}$ (Jóźwiak and Filipkowska 2019). The high sorptive capacity of chitosan results from primary amine groups, which are the main sorption centers for most of the pollutants having a negative charge in the solution (Jóźwiak et al. 2017). Its disadvantage, however, is its poor availability in regions where krill, shrimps or crabs are not fished. In addition, its initially low price has been raised in recent years due to a growing interest from the pharmaceutical industry that uses it to produce dietary supplements, e.g. glucosamine.

Cellulose is a raw material structurally similar to chitosan, however chitosan possesses an amine group that imparts a basic character to a compound. Due to the lack of the $-\mathrm{NH}_{2}$ group and the neutral nature, cellulose has a potentially low sorption capacity with respect to anionic dyes. But as a raw material, it can be many times cheaper and much more available than chitosan. In theory, introducing amine groups into the cellulose chains would lead to a material resembling chitosan in sorption properties and being more effective in anionic dyes sorption.
The sorption properties of aminated cotton fibers as well as unmodified cotton fibers against dyes popular in the anion industry (Reactive Black 5, Reactive Yellow 84, Acid Red 18 and Acid Yellow 23) were compared and investigated. The choice of cotton as a raw material for sorbent production was determined by: cellulose content $>99 \%$, large surface area of the material $\left(>100 \mathrm{~m}^{2} / \mathrm{g}\right.$ in aqueous solution) (Thakur 2015) as well as good application properties (easy separation of the material from the solution). Ammonia (ammonia water) was used as the aminating agent. The efficiency of the cellulose amination process was increased by pre-activation of cotton with epichlorohydrin.

\section{Materials and laboratory equipment}

Cotton fibers

"Bella Cotton" loose cotton fiber (Matopat, Poland) with the cellulose content $>99 \%$ (declared by the producer) and surface area of $137 \mathrm{~m}^{2} / \mathrm{g}$ (in distilled water) was used as cotton fibers in the tests.

\section{Dyes}

Reactive dyes: Reactive Black 5 (RB5), Reactive Yellow 84 (RY84); and acidic dyes: Acid Red 18 (AR18), Acid Yellow 23 (AY23) (Fig. 1), were purchased at the "BORUTA-ZACHEM SA" dyes production facility in Zgierz (Poland).

\section{Chemical reagents}

The following chemical reagents were used in the tests: 99\% epichlorohydrin (ACROS ORGANICS, Poland), 25\% ammonia (POCH S.A., Poland) 35-38\% hydrochloric acid (POCH S.A., Poland), and sodium hydroxide in microgranules (POCH S.A., Poland). All reagents were analytically pure or of higher grade.

\section{Laboratory equipment}

The following laboratory equipment was used in analyses: HI 221 pH-meter (Hanna Instruments, USA) $-\mathrm{pH}$ measurement and adjustment; FT/IR4700LE spectrometer (JASCO, Japan)_FTIR analysis of sorbent; FLASH 2000 analyzer (THERMO 

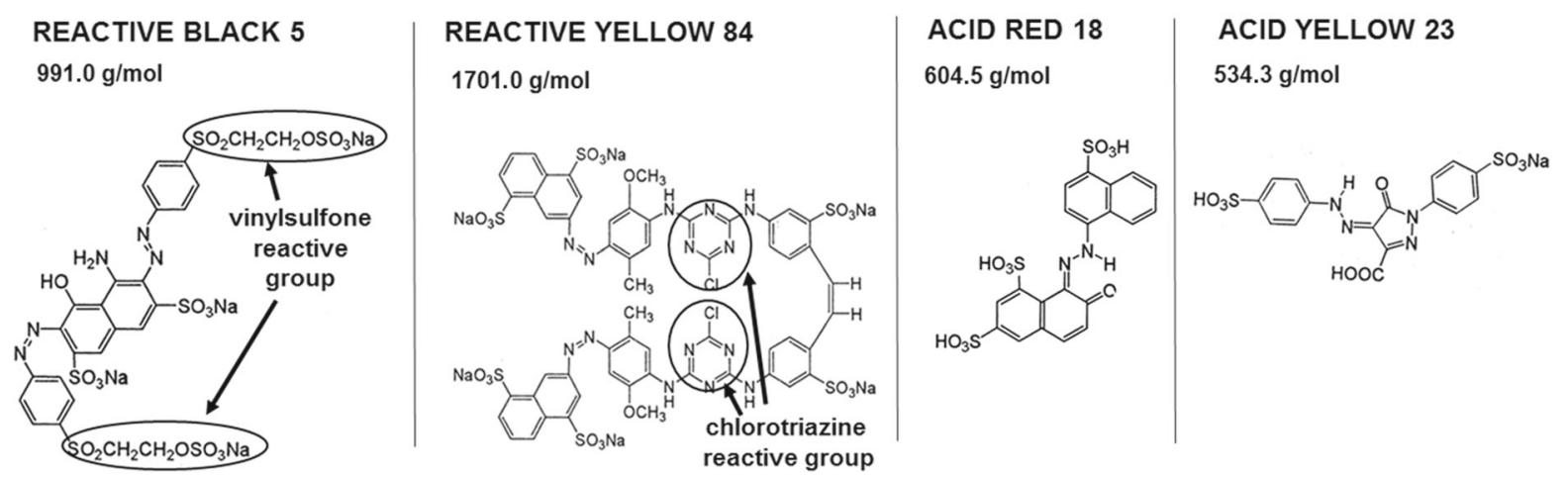

Fig. 1 Structural formulas of Reactive Black 5, Reactive Yellow 84, Acid Red 18 and, Acid Yellow 23, used in the study

SCIENTIFIC, USA)—elemental analysis (measurement of carbon and nitrogen content); UV-3100PC UV/VIS spectrophotometer (VWR International)determination of dye concentration; MS-53 M Magnetic Stirrers (GMI, USA) - sorption of dyes (kinetics); SK-71 Shaker (JEIO TECH, South Korea)sorption of dyes; and JWE-357 water bath with shaking (JW ELECTRONIC, Poland)-activation and amination of cotton fibers.

\section{Methodology}

Preparation of cotton fibers (CFs)

The cotton fibers were rinsed in $2 \mathrm{M} \mathrm{H}_{2} \mathrm{SO}_{4}$ and then in $2 \mathrm{M} \mathrm{NaOH}$. After filtration, they were washed with a large volume of distilled water to remove possible residues of wax and fragrances from the material and to loosen the structure of cellulose fibers. After drying at $105{ }^{\circ} \mathrm{C}, \mathrm{CFs}$ were stored in an airtight container at room temperature $\left(25^{\circ} \mathrm{C}\right)$, and afterwards soaked for $12 \mathrm{~h}$ in distilled water before use.

\section{Preparation of aminated cotton fibers (ACFs)}

CFs (100 g) were put into a conical flask $(500 \mathrm{~mL})$ to which $100 \mathrm{~g}$ of an epichlorohydrin solution $(\mathrm{ECH})$ (>99.0\%) were added. The epichlorohydrin solution in the flask (containing $\mathrm{CFs}$ ) was then subjected to $\mathrm{pH}$ correction (to $\mathrm{pH} 12$ ) with a $1 \mathrm{M} \mathrm{NaOH}$ solution. The flask was then protected with parafilm and placed in a shaking water bath set at $60^{\circ} \mathrm{C}, 150$ r.p.m. After 24 h, the cotton fibers were drained and washed with distilled water to remove unreacted ECH. After washing, they were put into a solution of ammonia $(400 \mathrm{~g}-25 \%)$ in a beaker $(600 \mathrm{~mL})$ protected with a latex membrane. After $24 \mathrm{~h}$ of ammonization, the fibers were filtered and washed with distilled water to remove any unreacted ammonia, and finally dried $\left(105^{\circ} \mathrm{C}\right)$. The aminated cotton fibers (ACFs) were soaked for $12 \mathrm{~h}$ in distilled water before use.

Research on the influence of solution $\mathrm{pH}$ on dye sorption efficiency

A sorbent $(1.0 \mathrm{~g}$ d.m.) was weighed into a series of conical flasks $(300 \mathrm{~mL})$, after which dye solutions of $200 \mathrm{~mL}, \mathrm{pH} 2-11$ and concentration of $50 \mathrm{mg} / \mathrm{L}$ were added to the flasks. The flasks were then placed on a laboratory shaker (150 r.p.m., vibration amplitude$25 \mathrm{~mm}$ ) for $2 \mathrm{~h}$. After a predetermined time, the samples $(10 \mathrm{~mL})$ were taken from the flasks to analyze the concentration of dye left in the solution. The $\mathrm{pH}$ value of the solutions after sorption was measured as well.

Research on dye sorption kinetics

The sorbent $(5 \mathrm{~g}$ d.m.) was weighed into beakers $(1000 \mathrm{~mL})$, after which dye solutions $(1000 \mathrm{~mL})$ with concentrations of 50,100 , and $250 \mathrm{mg} / \mathrm{L}$ and the optimal $\mathrm{pH}$ (established in point 3.2) were added to the beakers. The beakers were then placed on a magnetic stirrer (150 r.p.m.). At specific time intervals $(0,10$, $20,30,45,60,90,120,180,240,360 \mathrm{~min})$, the samples $(5 \mathrm{~mL})$ were collected from the solutions for spectrophotometric determination of the concentration of dye left in the solution. 
Research on the maximum sorption capacity against dyes

The sorbent (1.0 g d.m.) and dye solutions (200 mL) with optimal $\mathrm{pH}$ (established in point 3.2) and with concentrations of: $5,10,20,30,50,75,100,150,200$, and $250 \mathrm{mg} / \mathrm{L}$, were weighed into conical flasks $(300 \mathrm{~mL})$. The flasks were then placed on a laboratory shaker (150 r.p.m., vibration amplitude $-25 \mathrm{~mm}$ ). After the equilibrium time (point 3.3), samples of the solutions $(10 \mathrm{~mL})$ were collected from the conical flasks to analyze the concentration of dye that remained in them.

Analyses described in points 3.3-3.5 were conducted for 2 sorbents (CFs, ACFs) and 4 dyes (RB5, RY84, AR18, AY23). All experiments were carried out at $22^{\circ} \mathrm{C}$.

Calculation methods

The amount of the sorbed dye was calculated using the following formula (1):

$\mathbf{Q}=\left(\left(\mathbf{C}_{\mathbf{0}}-\mathbf{C}_{\mathbf{E}}\right) * \mathbf{V}\right) / \mathbf{m}$

The kinetics of dyes sorption on CFs and ACFs was described by pseudo-first order (2) and pseudo-second order (3) equations:

$$
\begin{aligned}
& \Delta \mathbf{q} / \Delta \mathbf{t}=\mathbf{k}_{\mathbf{1}} *\left(\mathbf{q}_{\mathbf{e}}-\mathbf{q}_{\mathbf{t}}\right) \\
& \Delta \mathbf{q} / \Delta \mathbf{t}=\mathbf{k}_{2} *\left(\mathbf{q}_{\mathbf{e}}-\mathbf{q}_{\mathbf{t}}\right)^{2}
\end{aligned}
$$

Sorption phases of dyes on cotton were described using a simplified model of intramolecular diffusion (4):

$\mathbf{q}_{\mathbf{t}}=\mathbf{k}_{\mathbf{d}} * \mathbf{t}^{0.5}$

Two popular sorption isotherms: Langmuir (5) and Freundlich (6), were used to determine the maximum sorption capacity of the sorbents:

$$
\begin{aligned}
& \mathbf{Q}=\left(\mathbf{Q}_{\mathbf{m a x}} * \mathbf{K}_{\mathbf{C}} * \mathbf{C}_{\mathbf{k}}\right) /\left(\mathbf{1}+\mathbf{K}_{\mathbf{C}} * \mathbf{C}_{\mathbf{k}}\right) \\
& \mathbf{Q}=\mathbf{k} * \mathbf{C}_{\mathbf{k}}^{\mathbf{n}}
\end{aligned}
$$

where $\mathrm{Q}$ - mass of sorbed dye (mg/g d.m.), $\mathrm{C}_{\mathrm{o}}$-initial dye concentration $(\mathrm{mg} / \mathrm{L}), \mathrm{C}_{\mathrm{E}}-$ dye concentration after sorption $(\mathrm{mg} / \mathrm{L}), \mathrm{V}$-volume of the solution (L), m-dose of the sorbent (g d.m.), $\mathrm{q}_{\mathrm{t}}$-momentary quantity of sorbed dye $(\mathrm{mg} / \mathrm{g}), \mathrm{q}_{\mathrm{e}}$-equilibrium amount of sorbed dye $(\mathrm{mg} / \mathrm{g})$, $\mathrm{t}$-sorption time (min), $\mathrm{k}_{1}$ - constant in the pseudo-first order equation (1/min), $\mathrm{k}_{2}$-constant in the pseudo-second order equation $(\mathrm{g} /(\mathrm{min} * \mathrm{mg})), \mathrm{k}_{\mathrm{di}}$-constant rate of intramolecular diffusion (mg/g $\left.\min ^{-0.5}\right), \mathrm{Q}_{\max }-\max -$ imum adsorptive capacity of the sorbent (mg/g d.m.), $\mathrm{K}_{\mathrm{c}}$ - constant in Langmuir equation (L/g d.m.), $\mathrm{C}_{\mathrm{k}}$ the concentration of the adsorbed substance at steady state $(\mathrm{mg} / \mathrm{L}), \mathrm{n}$-distribution factor (Freundlich isotherm) (-).

\section{Results and discussion}

Characteristics of cotton and aminated cotton FTIR spectra

The FTIR spectrum obtained for the unmodified cotton fibers ( $\mathrm{CFs}$ ) is typical of the cellulose-based materials (Fig. 2). The wide band of peaks in the range of $3600-3000 \mathrm{~cm}^{-1}$ indicates the presence of stretching vibrations of the $\mathrm{O}-\mathrm{H}$ polysaccharide bonds, whereas the peak at $2900 \mathrm{~cm}^{-1}$ is attributed to the tensile vibrations of the $\mathrm{C}-\mathrm{H}$ bonds of the polysaccharide (Hospodarova et al. 2018). The peak in the range of $1640-1650 \mathrm{~cm}^{-1}$ indicates the presence of water $\left(\mathrm{H}_{2} \mathrm{O}\right.$ molecules) in material structure (Kiefer et al. 2016). Peaks at 1429,1380 , and $1318 \mathrm{~cm}^{-1}$ are indicative of successive wagging in the plane, stretching and bending of the $\mathrm{C}-\mathrm{H}$ bond. Whereas peaks at 1336,1229 , and $1202 \mathrm{~cm}^{-1}$ correspond to the bending in the plane of the $\mathrm{O}-\mathrm{H}$ bond. Peaks at 1070, 1030, and $998 \mathrm{~cm}^{-1}$ correspond to the stretching of the $\mathrm{C}-\mathrm{O}$ bond. The presence of $\mathrm{C}-\mathrm{O}-\mathrm{C}$ binding - typical of the saccharide structures-is indicated by peaks at 1170 , 1108 , and $898 \mathrm{~cm}^{-1}$. In turn, the peak at $1175 \mathrm{~cm}^{-1}$ indicates the stretching in the plane of the saccharide cellulose ring (Chung et al. 2004).

In the case of an aminated cotton fiber spectrum, a peak in the range of $3250-3300 \mathrm{~cm}^{-1}$ indicates the stretching of the $\mathrm{N}-\mathrm{H}$ bond, whereas peaks at 980 , 930 , and $870 \mathrm{~cm}^{-1}$ are related to the fluctuation (wagging) of the primary amine $\mathrm{N}-\mathrm{H}$ bond. The peaks at $1360-1356,1280$, and $1247 \mathrm{~cm}^{-1}$ are indicative of the presence of the $\mathrm{C}-\mathrm{N}$ bond (Osler et al. 2017). In summary, the analysis of the FTIR spectra of the modified cotton fibers shows the presence of primary amine groups in the sorbent's structure and thus confirms the amination process did proceed during material ammonization. 


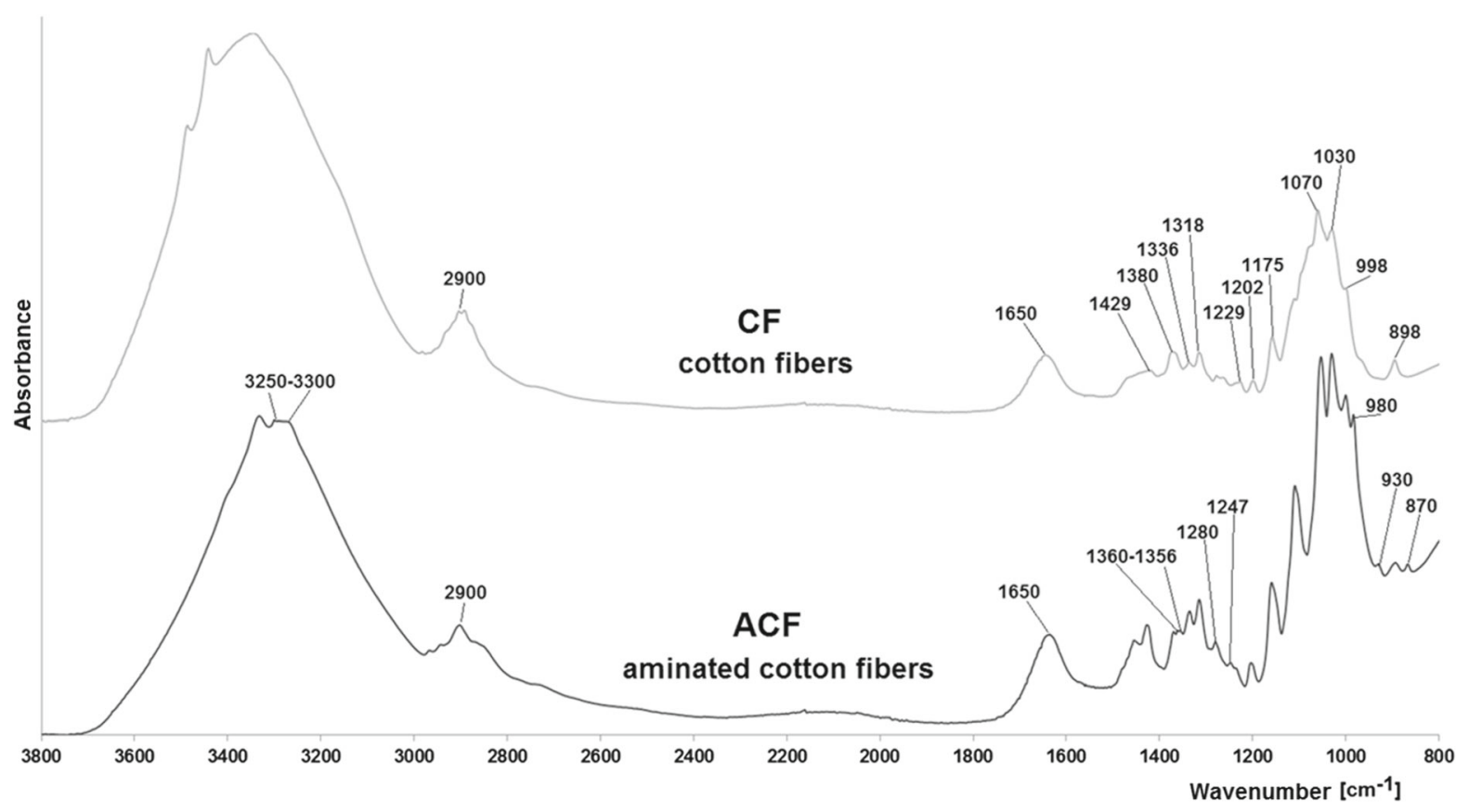

Fig. 2 IR spectra of cotton fibers (CFs) and aminated cotton fibers (ACFs)

Carbon and nitrogen content

The nitrogen content in the aminated cotton was from 0.65 to $0.71 \%$ (average $0.67 \%$ ), while in CFs it was $<0.1 \%$. This indicates that the process of cotton amination has taken place. The average carbon content in the analyzed samples was $38.66 \%$ for ACFs and $41.77 \%$ for CFs.

Influence of solution $\mathrm{pH}$ on dye sorption efficiency

The sorption efficiency of all tested anionic dyes (RB5, RY84, AR18, AY23) on CFs was the highest at $\mathrm{pH} 2$ and decreased with $\mathrm{pH}$ value increasing from 2 to 10. The binding of the RB5 reactive dye and acidic dyes AR18 and AY23 to ACFs was the most effective in the $\mathrm{pH}$ range of 3-4. The exception was the RY84 dye, sorption of which on ACFs was the most effective at $\mathrm{pH}$ 2. As with $\mathrm{CFs}$, an increase in $\mathrm{pH}$ value caused a decrease in ACFs sorption efficiency against all dyes tested (Fig. 3).

The higher sorption efficiency of anionic dyes at low solution $\mathrm{pH}$ is due to a positive charge gained by the surface of the sorbent. The protonated hydroxyl groups in CFs as well as the amine groups in ACFs interact electrostatically with the functional groups of dyes, generating a negative charge (e.g. sulfone groups) which supports the sorption of the anionic dyes tested (Chiu et al. 2018). Due to the higher susceptibility of $-\mathrm{NH}_{2}$ groups to protonation compared to the $-\mathrm{OH}$ groups, much better dye binding efficiency was demonstrated by the aminated sorbent (ACFs).

At high $\mathrm{pH}$ value, the functional groups of sorbents $\left(-\mathrm{OH},-\mathrm{NH}_{2}\right)$ can be deprotonated, as a result of which the sorbent gains a negative charge (Lindman et al. 2017; Pan et al. 2019) and this inhibits the binding process of anionic dyes. At high $\mathrm{pH}$, very low sorption efficiency of anionic dyes on CFs and ACFs may also result from competition of dyes with $\mathrm{OH}^{-}$ions (Jóźwiak et al. 2020).

The decrease in the sorption efficiency at $\mathrm{pH} 2$ (relative to $\mathrm{pH} 3$ and 4) observed in the case of RB5, AR18, and AY23 was probably due to the strong competition of dyes with $\mathrm{Cl}^{-}$ions and amine sorption centers on ACFs surface (Zhao et al. 2017). This was not observed for the RY84 dye, presumably due to the extremely high affinity of the reactive chlorotriazine groups to the amine groups. This is a phenomenon characteristic of sorbents having primary amine groups in their structure. A very similar tendency was observed in the sorption of RB5 and RY84 dyes on chitosan-based sorbents (Filipkowska and Jóźwiak 
Fig. 3 Influence of solution $\mathrm{pH}$ on the efficiency of dye sorption: a RB5, b RY84, c AR18, and d AY23 on CFs and ACFs, temp. $22{ }^{\circ} \mathrm{C}$
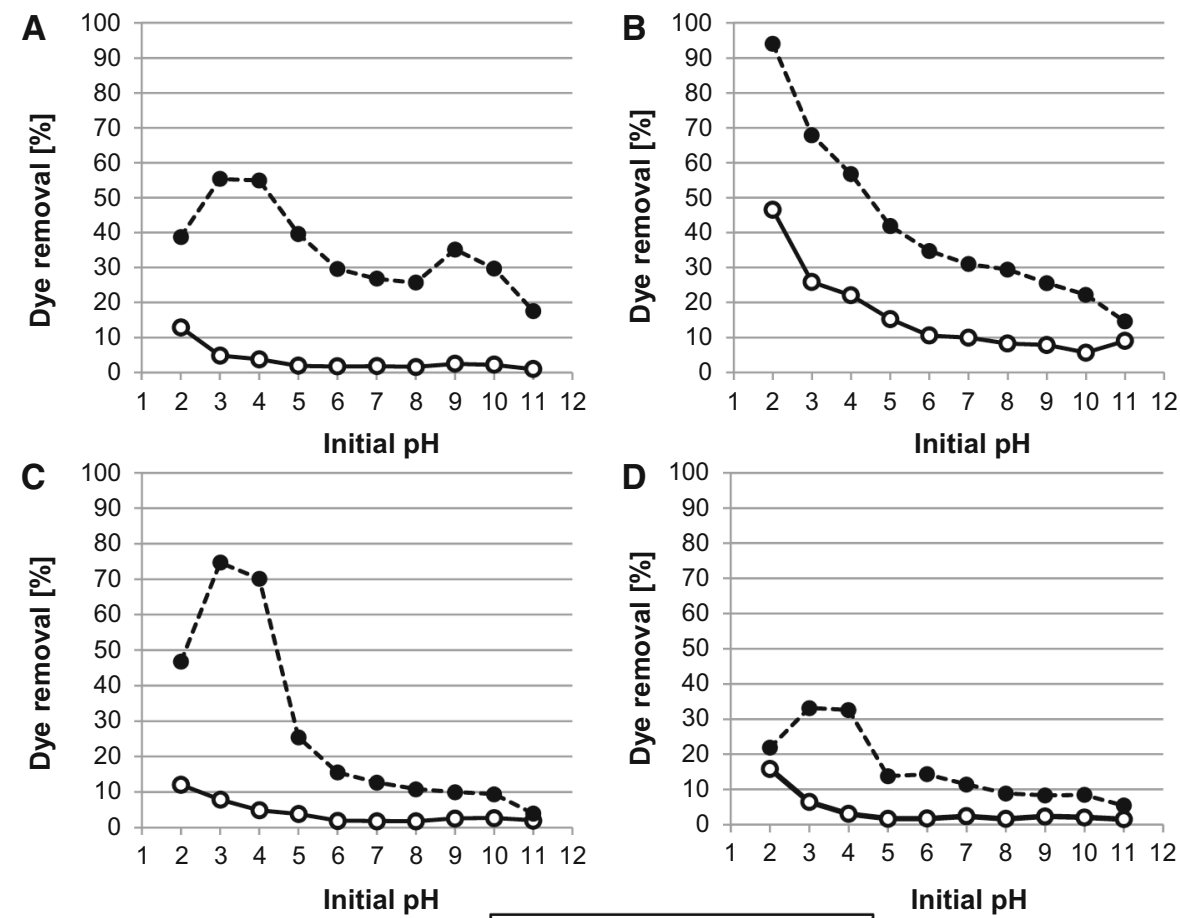

$\multimap$ CF $\quad--$ ACF
2013). This may provide further evidence for the presence of amine groups on the surface of ACFs.

A similar tendency observed for various anionic dyes (e.g. RB5 and AR18/AY23), differing in their molecular mass as well as the number and type of functional groups, points to the same, simple sorption mechanism based on electrostatic interactions between the dye and the sorbent. This is the likely cause of similar results obtained for a variety of anionic dyes (Lipatova et al. 2018).

Cotton sorbents used in the research influenced the $\mathrm{pH}$ change of the solution they had contact with (Fig. 4a-d). At the initial solution $\mathrm{pH}$ ranging from 6 to 10 , after sorption of dyes on $\mathrm{CFs}$ the $\mathrm{pH}$ was in the range from 7.1 to 8.1 , and in the case of $\mathrm{ACFs}$ - in the range from 7.5 to 8.3. This is due to solution's tending for the $\mathrm{pH}_{\mathrm{PZC}}$ characteristic of the sorbent, which for CFs and ACFs reached $\mathrm{pH}_{\mathrm{PZC}}=7.85$ and $\mathrm{pH}_{\mathrm{PZC}-}$ $=8.15$, respectively (Fig. $4 \mathrm{e}-\mathrm{f}$ ). The higher $\mathrm{pH}_{\mathrm{PZC}}$ value determined for ACFs compared to CFs is due to the presence of amine functional groups that affect the alkaline nature of the sorbent (Deng et al. 2016; Filipkowska et al. 2018).

The process of dyeing materials using anionic (acidic) dyes is usually carried out in an acidic environment, and post-production wastewater usually has a pH value of 3-4 (Mihułka et al. 2003). For this reason, the next stages of the research (tests into the sorption kinetics and sorption capacity) were carried out at $\mathrm{pH} 3$ for all dyes and sorbents tested.

Kinetics of dyes sorption

The time needed to reach the sorption equilibrium for anionic dyes on $\mathrm{CFs}$, regardless of their initial concentration, was $240 \mathrm{~min}$, while in the case of ACFs it was shorter and did not exceed $120 \mathrm{~min}$ (Fig. 5). Both in the case of CFs and ACFs, the dye binding intensity was the highest at the initial sorption phase and depended on the initial concentration of dyes (Tables 1, 2). The increase in the binding intensity of dyes on the surface of sorbents together with the increase of their concentration in the solution was most likely due to the increasing probability of dye molecules collision with active sorbent centers.

Regardless of the type of sorbent and dye tested, the largest match to the experimental data was shown by the pseudo-secondary model (higher values of $\mathrm{R}^{2}$ and smaller values of Chi square- $\chi^{2}$ ) (Table 1 ). The $\mathrm{q}_{\mathrm{e}, \mathrm{cal}}$ constant in most cases increased with the initial 

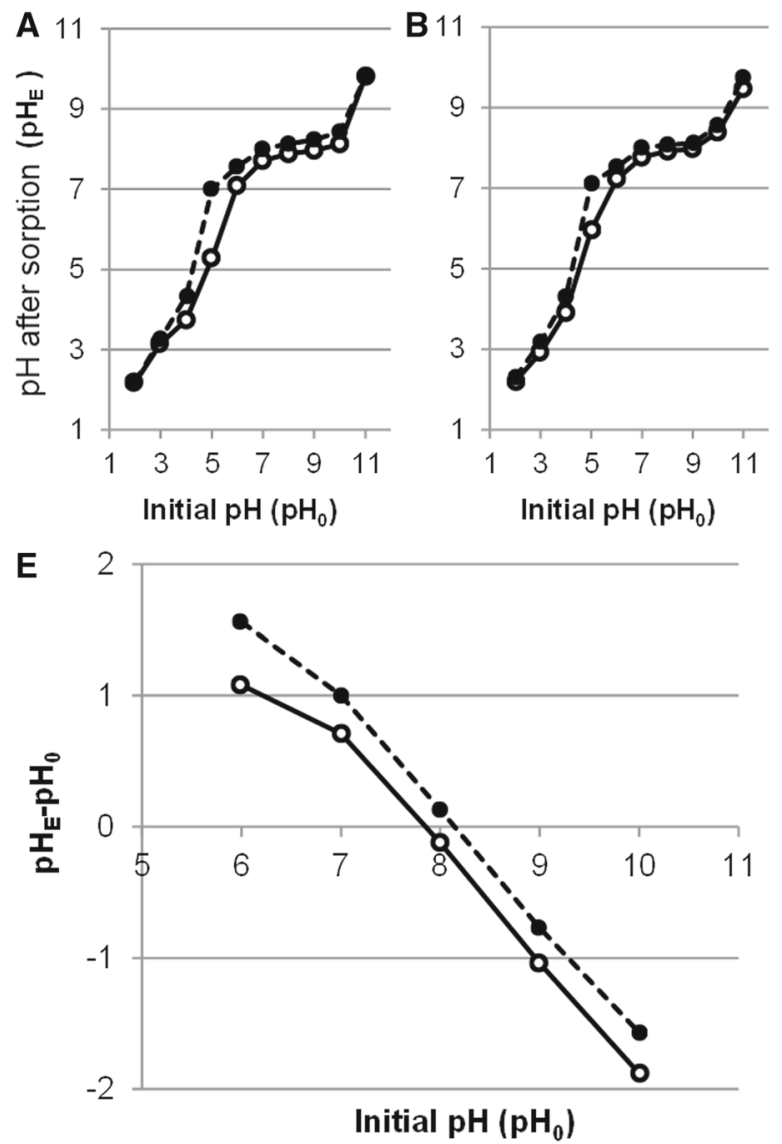
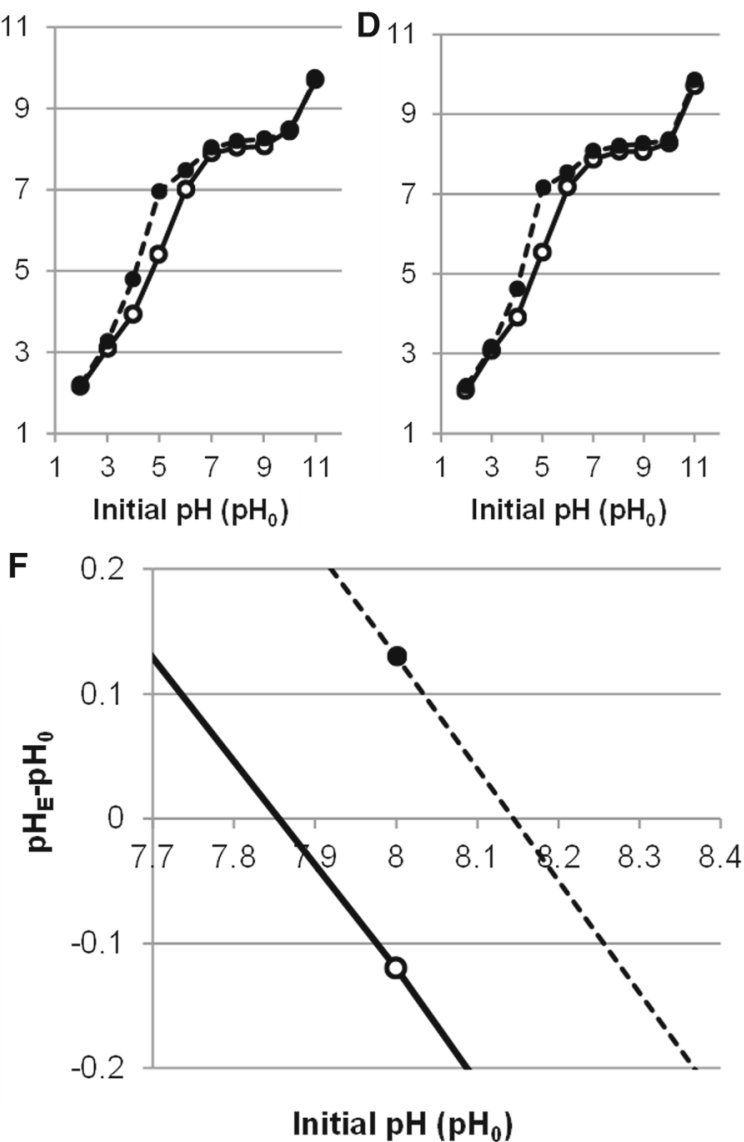

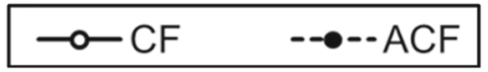

Fig. 4 pH values of solutions after sorption of dyes: a RB5, b RY84, c AR18, and d AY23 on CFs and ACFs. e Determination of pH of sorbents tested, $\mathbf{f}$ Close-up to the intersection of the $\mathrm{X}$ axis in $\mathbf{e}$, temp. $22{ }^{\circ} \mathrm{C}$

colorant concentration. This is a typical phenomenon of the sorption of anionic dyes on biosorbents (Dehvari et al. 2016; Oyelude et al. 2017).

The sorption of the dyes tested, both on CFs and ACFs, occurred in two distinct phases (Table 2). In the first phase, dyes were associated with the most available sorption centers, located mainly in the top layers of the sorbent. This phase was short but intense. In the second phase, the dyes were filled with active centers, located in deeper, less accessible layers of the sorbent. Therefore, the second phase lasted longer than the first one and was characterized by a lower efficiency.

As expected, the $\mathrm{k}_{\mathrm{d} 1}$ constant determined from the intramolecular diffusion model increased with the increase of the initial dye concentrations. As already mentioned, this was due to the greater chance of sorbate colliding with the active site in the system with a higher concentration of dye. The increasing intensity of dye sorption along with the concentration of the colorant in the first phase of the process resulted in its decrease in the second phase (Table 2). In the second phase, the growing competition between dyes for the last unsaturated sorption centers translated into the lower sorption efficiency.

The sorption intensity of the tested dyes on ACFs was many times higher than on CFs (qe valuesTable $1, \mathrm{k}_{\mathrm{d} 1} / \mathrm{k}_{\mathrm{d} 2}$ values-Table 2). Since CFs mainly consists of cellulose ( $>99 \%$ ), this sorbent had mainly hydroxyl functional groups. In turn, apart from hydroxyl groups, the ammonized cotton fibers (ACFs) had also amine groups. At low solution $\mathrm{pH}(\mathrm{pH} 3)$, protonation was observed to occur for the majority of 

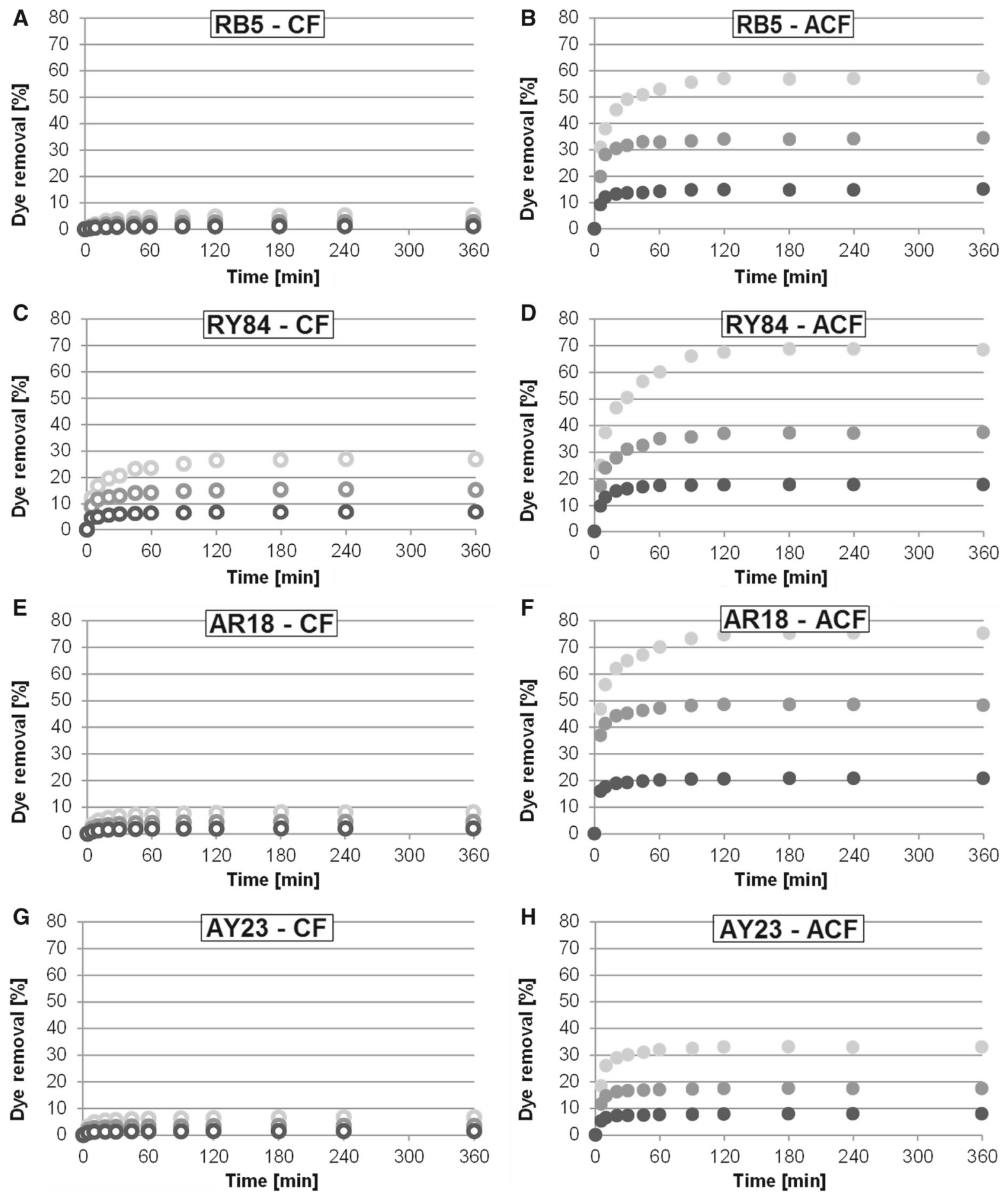

\begin{tabular}{cc}
\hline ACF & $50 \mathrm{mg} \mathrm{RB5} / \mathrm{L}$ \\
- experimental data & $0100 \mathrm{mg} \mathrm{RB5} / \mathrm{L}$ \\
& $\circ 250 \mathrm{mg} \mathrm{RB5} / \mathrm{L}$
\end{tabular}

$\begin{array}{cc}\text { CF } & 50 \mathrm{mg} \mathrm{RB5} / \mathrm{L} \\ \text { - experimental data } & 100 \mathrm{mg} \mathrm{RB5} / \mathrm{L} \\ & 250 \mathrm{mg} \mathrm{RB5} / \mathrm{L}\end{array}$


4 Fig. 5 Kinetics of dye sorption: a RB5 on CFs, b RB5 on ACFs, c RY84 on CFs, d RY84 on ACFs, e AR18 on CFs, f AR18 on ACFs, g AY23 on CFs, h AY23 on ACFs. Solution pH 3, temp. $22^{\circ} \mathrm{C}$

the primary amine groups and for only a small fraction of the hydroxyl groups.

$$
\begin{aligned}
-\mathrm{NH}_{2}+\mathrm{H}_{3} \mathrm{O}^{+} \rightarrow & -\mathrm{NH}_{3}^{+} \\
& \left.+\mathrm{H}_{2} \mathrm{O} \text { (high efficiency at } \mathrm{pH} 3\right) \\
-\mathrm{OH}+\mathrm{H}_{3} \mathrm{O}^{+} \rightarrow & -\mathrm{OH}_{2}^{+} \\
& \left.+\mathrm{H}_{2} \mathrm{O} \text { (low efficiency at } \mathrm{pH} 3\right)
\end{aligned}
$$

The ACFs surfaces had a larger total positive charge compared to the $\mathrm{CFs}$, which significantly intensified and accelerated the sorption process of anionic dyes. This is also an explanation of the shorter duration of phase 1 and 2 as well as the equilibrium time of dye sorption on ACFs as compared to CFs.

\section{Maximum sorption capacity}

The sorption of the tested dyes on CFs and ACFs is better described with the Langmuir isotherm than with the Freundlich isotherm, as evidenced by the higher values of $\mathrm{R}^{2}$ and lower values of Chi square $\left(\chi^{2}\right)$ (Table 3). A better fit of the Langmuir model than of the Freundlich model to the experimental data may suggest that the dye molecules form a monolayer on the sorbent's surface. The shape of the Langmuir isotherm (Fig. 6) suggests that only one dye molecule

\begin{tabular}{|c|c|c|c|c|c|c|c|c|c|c|c|}
\hline \multirow[t]{2}{*}{ Dye } & \multirow[t]{2}{*}{ Sorbent } & \multirow{2}{*}{$\begin{array}{l}\text { Conc. of dye } \\
(\mathrm{mg} / \mathrm{L})\end{array}$} & \multicolumn{4}{|c|}{ Pseudo-first order model } & \multicolumn{4}{|c|}{ Pseudo-second order model } & \multirow{2}{*}{$\begin{array}{l}\text { Exp. data } \\
\text { qe.exp }_{(\mathrm{mmol} / \mathrm{g})}\end{array}$} \\
\hline & & & $\begin{array}{l}\mathrm{q}_{\text {e.cal }} \\
(\mathrm{mg} / \mathrm{g})\end{array}$ & $\begin{array}{l}\mathrm{K}_{1} \\
(1 / \mathrm{min})\end{array}$ & $\begin{array}{l}\mathrm{R}^{2} \\
-\end{array}$ & $\begin{array}{l}\chi^{2} \\
-\end{array}$ & $\begin{array}{l}\mathrm{q}_{\mathrm{e} . \mathrm{cal}} \\
(\mathrm{mg} / \mathrm{g})\end{array}$ & $\begin{array}{l}\mathrm{K}_{2} \\
(\mathrm{~g} / \mathrm{mg} * \min )\end{array}$ & $\begin{array}{l}\mathrm{R}^{2} \\
-\end{array}$ & $\begin{array}{l}\chi^{2} \\
-\end{array}$ & \\
\hline \multirow[t]{6}{*}{ RB5 } & \multirow[t]{3}{*}{$\mathrm{CFs}$} & 50 & 2.49 & 0.045 & 0.988 & 0.047 & 2.78 & 0.021 & 0.994 & 0.046 & 2.62 \\
\hline & & 100 & 2.65 & 0.051 & 0.988 & 0.064 & 2.92 & 0.025 & 0.998 & 0.010 & 2.78 \\
\hline & & 250 & 2.77 & 0.060 & 0.986 & 0.084 & 3.03 & 0.028 & 0.999 & 0.006 & 2.89 \\
\hline & \multirow[t]{3}{*}{ ACFs } & 50 & 27.20 & 0.127 & 0.963 & 1.375 & 28.96 & 0.007 & 0.996 & 0.135 & 28.52 \\
\hline & & 100 & 33.28 & 0.178 & 0.991 & 0.294 & 34.85 & 0.009 & 0.995 & 0.235 & 34.44 \\
\hline & & 250 & 35.97 & 0.188 & 0.985 & 0.535 & 37.66 & 0.009 & 0.998 & 0.099 & 37.64 \\
\hline \multirow[t]{6}{*}{ RY84 } & \multirow[t]{3}{*}{$\mathrm{CFs}$} & 50 & 12.61 & 0.097 & 0.949 & 0.951 & 13.59 & 0.011 & 0.992 & 0.130 & 13.45 \\
\hline & & 100 & 14.55 & 0.168 & 0.963 & 0.570 & 15.38 & 0.018 & 0.994 & 0.092 & 15.31 \\
\hline & & 250 & 16.15 & 0.184 & 0.955 & 0.853 & 16.98 & 0.019 & 0.991 & 0.178 & 17.03 \\
\hline & \multirow[t]{3}{*}{ ACFs } & 50 & 32.91 & 0.066 & 0.960 & 2.687 & 35.77 & 0.003 & 0.994 & 0.315 & 34.21 \\
\hline & & 100 & 35.59 & 0.104 & 0.966 & 1.767 & 38.17 & 0.004 & 0.997 & 0.139 & 37.45 \\
\hline & & 250 & 43.55 & 0.144 & 0.988 & 0.639 & 45.92 & 0.005 & 0.998 & 0.078 & 44.54 \\
\hline \multirow[t]{6}{*}{ AR18 } & \multirow[t]{3}{*}{$\mathrm{CFs}$} & 50 & 3.83 & 0.095 & 0.968 & 0.176 & 4.13 & 0.035 & 0.997 & 0.014 & 4.09 \\
\hline & & 100 & 4.27 & 0.098 & 0.965 & 0.217 & 4.59 & 0.032 & 0.997 & 0.017 & 4.53 \\
\hline & & 250 & 4.74 & 0.105 & 0.981 & 0.133 & 5.07 & 0.032 & 0.999 & 0.001 & 4.97 \\
\hline & \multirow[t]{3}{*}{ ACFs } & 50 & 35.61 & 0.176 & 0.959 & 1.588 & 37.57 & 0.008 & 0.994 & 0.251 & 37.61 \\
\hline & & 100 & 47.07 & 0.278 & 0.985 & 0.666 & 48.57 & 0.012 & 0.999 & 0.055 & 48.21 \\
\hline & & 250 & 50.21 & 0.286 & 0.983 & 0.813 & 51.80 & 0.012 & 0.998 & 0.085 & 52.05 \\
\hline \multirow[t]{6}{*}{ AY23 } & \multirow[t]{3}{*}{$\mathrm{CFs}$} & 50 & 3.15 & 0.132 & 0.977 & 0.082 & 3.35 & 0.061 & 0.996 & 0.018 & 3.33 \\
\hline & & 100 & 3.31 & 0.164 & 0.977 & 0.083 & 3.49 & 0.078 & 0.998 & 0.007 & 3.50 \\
\hline & & 250 & 3.51 & 0.172 & 0.973 & 0.100 & 3.69 & 0.078 & 0.997 & 0.012 & 3.68 \\
\hline & \multirow[t]{3}{*}{ ACFs } & 50 & 16.03 & 0.162 & 0.989 & 0.191 & 16.86 & 0.016 & 0.997 & 0.075 & 16.49 \\
\hline & & 100 & 17.08 & 0.212 & 0.994 & 0.110 & 17.74 & 0.023 & 0.998 & 0.030 & 17.44 \\
\hline & & 250 & 19.16 & 0.213 & 0.989 & 0.204 & 19.94 & 0.020 & 0.999 & 0.023 & 19.77 \\
\hline
\end{tabular}
can attach to one sorption center.

Table 1 Kinetic parameters of dye sorption on CFs and ACFs, determined on the basis of the pseudo-first order model and the pseudo-second order model 
Table 2 Constant dye diffusion rates determined on the basis of a simplified model of intramolecular diffusion

\begin{tabular}{|c|c|c|c|c|c|c|c|c|}
\hline \multirow[t]{2}{*}{ Dye } & \multirow[t]{2}{*}{ Sorbent } & \multirow{2}{*}{$\begin{array}{l}\text { Conc. of dye } \\
(\mathrm{mg} / \mathrm{L})\end{array}$} & \multicolumn{3}{|c|}{ The first phase of sorption } & \multicolumn{3}{|c|}{ The second phase of sorption } \\
\hline & & & $\begin{array}{l}\mathrm{k}_{\mathrm{d} 1} \\
\left(\mathrm{mg} \mathrm{g}^{-1} * \min ^{-0.5}\right)\end{array}$ & $\begin{array}{l}\text { Phase duration } \\
\text { (min) }\end{array}$ & $\begin{array}{l}\mathrm{R}^{2} \\
-\end{array}$ & $\begin{array}{l}\mathrm{k}_{\mathrm{d} 2} \\
\left(\mathrm{mg} * \mathrm{~g}^{-1} * \min ^{-0.5}\right)\end{array}$ & $\begin{array}{l}\text { Phase duration } \\
(\mathrm{min})\end{array}$ & $\begin{array}{l}\mathrm{R}^{2} \\
-\end{array}$ \\
\hline \multirow[t]{6}{*}{ RB5 } & \multirow[t]{3}{*}{ CFs } & 50 & 0.3089 & 60 & 0.9700 & 0.0556 & 180 & 0.9442 \\
\hline & & 100 & 0.3416 & 60 & 0.9729 & 0.0411 & 180 & 0.9272 \\
\hline & & 250 & 0.3718 & 60 & 0.9542 & 0.0373 & 180 & 0.9151 \\
\hline & \multirow[t]{3}{*}{ ACFs } & 50 & 5.1481 & 20 & 0.9538 & 0.8762 & 100 & 0.9559 \\
\hline & & 100 & 8.8986 & 10 & 0.9999 & 0.6725 & 110 & 0.8949 \\
\hline & & 250 & 9.6219 & 10 & 0.9538 & 0.6685 & 110 & 0.9739 \\
\hline \multirow[t]{6}{*}{ RY84 } & \multirow[t]{3}{*}{ CFs } & 50 & 2.2608 & 30 & 0.9690 & 0.2182 & 210 & 0.9590 \\
\hline & & 100 & 3.7609 & 20 & 0.9951 & 0.2188 & 220 & 0.8453 \\
\hline & & 250 & 4.0685 & 20 & 0.9484 & 0.1922 & 220 & 0.8763 \\
\hline & \multirow[t]{3}{*}{ ACFs } & 50 & 5.3381 & 20 & 0.9975 & 1.7412 & 100 & 0.9794 \\
\hline & & 100 & 7.6572 & 10 & 0.9998 & 1.3256 & 90 & 0.9119 \\
\hline & & 250 & 10.446 & 10 & 0.9901 & 0.8733 & 90 & 0.8293 \\
\hline \multirow[t]{6}{*}{ AR18 } & \multirow[t]{3}{*}{ CFs } & 50 & 0.6184 & 30 & 0.9653 & 0.0683 & 210 & 0.8814 \\
\hline & & 100 & 0.6792 & 30 & 0.9544 & 0.0616 & 210 & 0.8654 \\
\hline & & 250 & 0.7815 & 30 & 0.9619 & 0.0500 & 210 & 0.9141 \\
\hline & \multirow[t]{3}{*}{$\mathrm{ACFs}$} & 50 & 9.1367 & 10 & 0.9818 & 0.9938 & 110 & 0.9790 \\
\hline & & 100 & 13.713 & 10 & 0.9641 & 0.6704 & 110 & 0.9590 \\
\hline & & 250 & 14.620 & 10 & 0.9568 & 0.6444 & 110 & 0.9418 \\
\hline \multirow[t]{6}{*}{ AY23 } & \multirow[t]{3}{*}{ CFs } & 50 & 0.6367 & 20 & 0.9690 & 0.0529 & 220 & 0.9135 \\
\hline & & 100 & 0.6747 & 20 & 0.9391 & 0.0471 & 220 & 0.8570 \\
\hline & & 250 & 0.7092 & 20 & 0.9227 & 0.0416 & 220 & 0.9136 \\
\hline & \multirow[t]{3}{*}{ ACFs } & 50 & 4.1106 & 10 & 0.9999 & 0.3047 & 110 & 0.9387 \\
\hline & & 100 & 4.7186 & 10 & 0.9914 & 0.3007 & 110 & 0.8605 \\
\hline & & 250 & 5.2911 & 10 & 0.9896 & 0.2491 & 110 & 0.9859 \\
\hline
\end{tabular}

Table 3 Constants determined from Langmuir model and from Freundlich model

\begin{tabular}{|c|c|c|c|c|c|c|c|c|c|}
\hline \multirow[t]{2}{*}{ Dye } & \multirow[t]{2}{*}{ Sorbent } & \multicolumn{4}{|c|}{ Langmuir model } & \multicolumn{4}{|c|}{ Freundlich model } \\
\hline & & $\begin{array}{l}\mathrm{Q}_{\max } \\
(\mathrm{mg} / \mathrm{g})\end{array}$ & $\begin{array}{l}\mathrm{K}_{\mathrm{C}} \\
(\mathrm{L} / \mathrm{mg})\end{array}$ & $\begin{array}{l}\mathrm{R}^{2} \\
-\end{array}$ & $\begin{array}{l}\chi^{2} \\
-\end{array}$ & $\begin{array}{l}\mathrm{k} \\
-\end{array}$ & $\begin{array}{l}\mathrm{n} \\
(\mathrm{L} / \mathrm{g})\end{array}$ & $\begin{array}{l}\mathrm{R}^{2} \\
-\end{array}$ & $\begin{array}{l}\chi^{2} \\
-\end{array}$ \\
\hline \multirow[t]{2}{*}{ RB5 } & CFs & 2.74 & 0.520 & 0.939 & 0.028 & 1.788 & 0.088 & 0.910 & 0.036 \\
\hline & ACFs & 36.77 & 0.195 & 0.981 & 3.782 & 12.193 & 0.225 & 0.931 & 5.350 \\
\hline \multirow[t]{2}{*}{ RY84 } & CFs & 15.90 & 0.224 & 0.965 & 0.690 & 6.367 & 0.184 & 0.872 & 2.181 \\
\hline & ACFs & 43.32 & 0.279 & 0.977 & 6.216 & 15.552 & 0.214 & 0.927 & 7.485 \\
\hline \multirow[t]{2}{*}{ AR18 } & CFs & 4.70 & 0.169 & 0.935 & 0.130 & 2.002 & 0.168 & 0.912 & 0.219 \\
\hline & ACFs & 54.23 & 0.137 & 0.993 & 0.918 & 14.536 & 0.264 & 0.878 & 16.585 \\
\hline \multirow[t]{2}{*}{ AY23 } & CFs & 3.58 & 0.811 & 0.935 & 0.025 & 2.622 & 0.064 & 0.724 & 0.118 \\
\hline & ACFs & 19.35 & 0.188 & 0.977 & 0.558 & 7.177 & 0.197 & 0.841 & 3.978 \\
\hline
\end{tabular}

The sorption capacity of ACFs relative to the RB5, RY84, AR18 and AY23 dyes was successively: $36.77 \mathrm{mg} / \mathrm{g}, 43.32 \mathrm{mg} / \mathrm{g}, 54.23 \mathrm{mg} / \mathrm{g}$, and $19.35 \mathrm{mg} /$ $\mathrm{g}$, being many times higher than that of CFs, which accounted for $2.84 \mathrm{mg} \mathrm{RB} 5 / \mathrm{g}, 15.90 \mathrm{mg} \mathrm{RY} 84 / \mathrm{g}$, $4.70 \mathrm{mg} \mathrm{AR} 18 / \mathrm{g}$, and $3.58 \mathrm{mg} \mathrm{AY23/g}$, respectively 

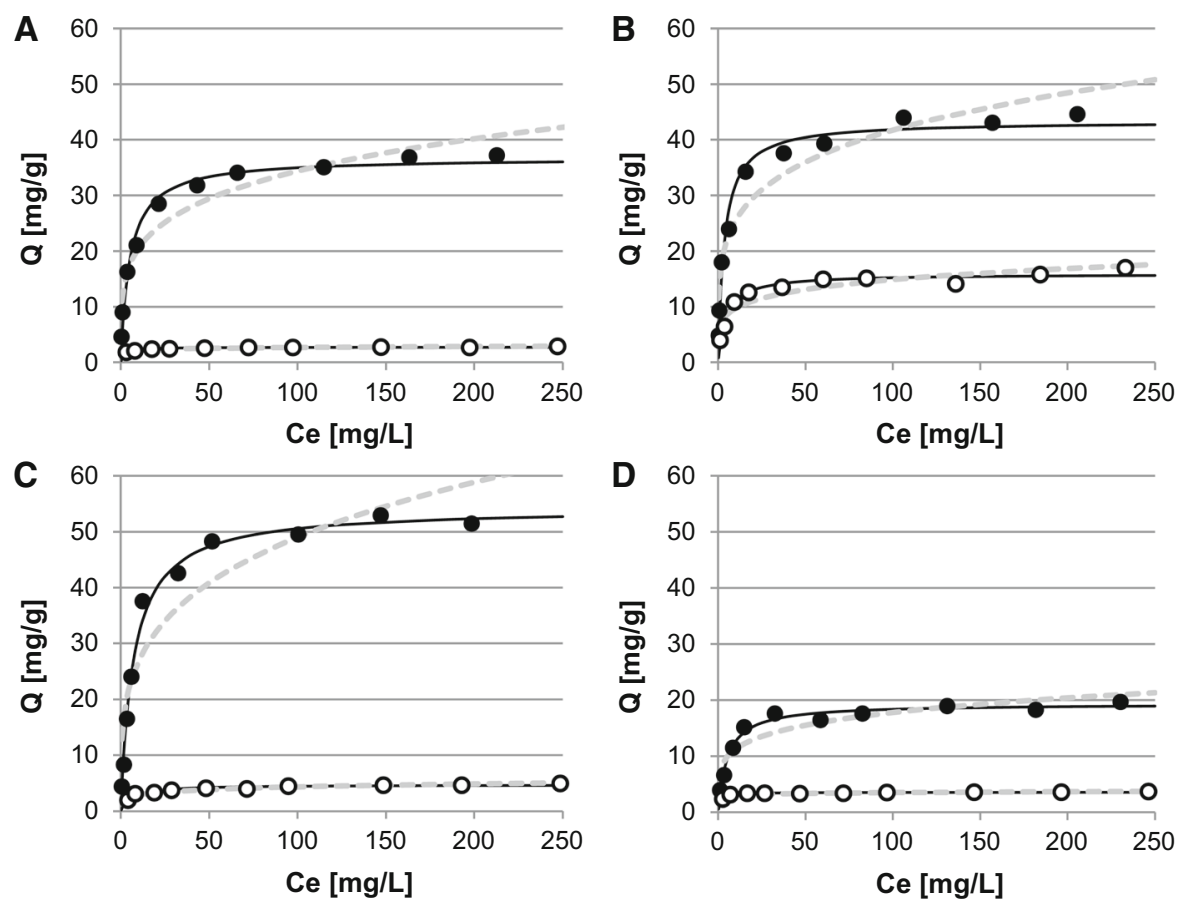

\begin{tabular}{|lll|}
\hline- & ACF - experimental data & - Langmuir model \\
- & CF - experimental data & ---- Freundlich model \\
\hline
\end{tabular}

Fig. 6 Dye sorption isotherms: a RB5, b RY84, c AR18, d AY23 on CFs and ACFs. Solution pH 3, temp. $22^{\circ} \mathrm{C}$

(Table 3, Fig. 6). In general, the lower $\mathrm{K}_{\mathrm{C}}$ values calculated for ACFs indicate a greater effect of the initial dye concentration on the efficiency of sorption compared to CFs.

The higher sorption capacity of ACFs compared to CFs was mainly due to the possibility of obtaining a larger total positive charge on the surface of the sorbent and thus a stronger interaction with anionic dyes, which is explained in points 3.2 and 3.3.

The higher sorption capacity of ACFs can also be caused by the more loose structure of cotton fibers. Presumably, the positively charged chains of aminated cellulose were repelled electrostatically at low $\mathrm{pH}$, which could increase the distance between them. As a result, the sorbent was swelling. This increased its specific surface as well as the availability of sorption centers located in its deeper layers, which translated into its better sorption properties. Probably due to the neutral nature of cellulose (Cumpstey 2013) and lower susceptibility of -OH groups to protonation (compared to $-\mathrm{NH}_{2}$ ), the structure of unmodified cotton fibers (CFs) remained compact even at low $\mathrm{pH}(\mathrm{pH}$ 2-3).
Differences between the sorption efficiencies of individual dyes could result from their different molar masses, which affected their ability to penetrate the sorbent's structure. The type and amount of acidic/ reactive functional groups, affecting the nature and strength of dye molecules interaction with the active sorbent centers, could be of great importance as well.

\section{Summary}

The ammonization of cotton fibers pre-activated with ECH leads to the amination of the cellulose contained therein. Due to the presence of primary amine groups, the ammonized (aminated) cotton (ACFs) shows much better sorption properties against anionic dyes than the unmodified cotton (CFs) does. The sorption capacities of ACFs against the tested dyes were by 170 to even $1240 \%$ higher than in the case of CFs.

The efficiency of dyes sorption on $\mathrm{CF}$ and ACF sorbents largely depends on the $\mathrm{pH}$ of the solution in which the sorption takes place. The binding of anionic dyes to CFs is most effective at $\mathrm{pH} 2$, whereas to 
ACFs - at $\mathrm{pH} 3-4$. In the $\mathrm{pH}$ range of 3-11, the sorption performance decreases with increasing $\mathrm{pH}$, which is due to the change of the charge on sorbent's surface.

ACFs and CFs cause changes in the $\mathrm{pH}$ value of the sorption solution. The system tends to obtain a $\mathrm{pH}$ value close to the $\mathrm{pH}_{\mathrm{PZC}}$ value of the sorbent. Due to the cellulose amination process occurring during the ammonium treatment of cotton (incorporation of basic $-\mathrm{NH}_{2}$ groups into sorbent's structure), the $\mathrm{pH}_{\mathrm{PZC}}$ value for ACFs is higher than for CFs.

The sorption of anionic dyes on CFs and ACFs occurs in two phases. The first phase involves fast and intense bonding of colorants with the most accessible sorption centers, located mainly in the top layers of the sorbent. In the second, longer and less intensive, phase the dyes compete with each other and fill the last free active centers located in the less available sorbent layers. The intensity of dyes sorption on CFs/ACFs is the highest at the initial phase of the process. In addition, the dye sorption rate increases with increasing initial concentration, which results from the probability of dye molecules colliding with the active sorbent centers.

The time needed to reach sorption equilibrium of anionic dyes on ACFs (120 min) is much shorter than on CFs (240 min). This is due to the presence of amine groups capable of easy protonation in the ACFs structure. A strong interaction of $-\mathrm{NH}_{3}{ }^{+}$with dye anions accelerates their binding on sorbent's surface and shortens process duration.

Acknowledgments This study was financed under Project No. 18.610.008-300 of the University of Warmia and Mazury in Olsztyn, Poland.

Open Access This article is licensed under a Creative Commons Attribution 4.0 International License, which permits use, sharing, adaptation, distribution and reproduction in any medium or format, as long as you give appropriate credit to the original author(s) and the source, provide a link to the Creative Commons licence, and indicate if changes were made. The images or other third party material in this article are included in the article's Creative Commons licence, unless indicated otherwise in a credit line to the material. If material is not included in the article's Creative Commons licence and your intended use is not permitted by statutory regulation or exceeds the permitted use, you will need to obtain permission directly from the copyright holder. To view a copy of this licence, visit http://creativecommons.org/licenses/by/4.0/.

\section{References}

Chiu CW, Wu MT, Lee JCM, Cheng TY (2018) Isothermal adsorption properties for the adsorption and removal of reactive Blue 221 dye from aqueous solutions by crosslinked $\beta$-chitosan glycan as acid-resistant adsorbent. Polymers 10:1-21. https://doi.org/10.3390/ polym 10121328

Chung C, Lee M, Choe EK (2004) Characterization of cotton fabric scouring by FT-IR ATR spectroscopy. Carbohyd Polym 58:417-420

Cumpstey I (2013) Chemical modification of polysaccharides. ISRN Organic Chemistry, Article ID 417672. https://doi. org/10.1155/2013/417672

Dehvari M, Ghaneian MT, Ebrahimi A, Jamshidi B, Mootab M (2016) Removal of reactive blue 19 dyes from textile wastewater by pomegranate seed powder: isotherm and kinetic studies. Int J Env Health Eng 5:1-9. https://doi.org/ 10.4103/2277-9183.179204

Deng H, Ning J, Wang X (2016) Amino-functionalized cotton fiber for enhanced adsorption of active brilliant red X-3B from aqueous solution. Microsc Res Tech 79:1200-1207

Farooq MU, Jalees MI, Iqbal A, Zahra N, Kiran A (2019) Characterization and adsorption study of biosorbents for the removal of basic cationic dye: kinetic and isotherm analysis. Desalin Water Treat 160:333-342

Filipkowska U, Jóźwiak T (2013) Application of chemicallycross-linked chitosan for the removal of Reactive Black 5 and Reactive Yellow 84 dyes from aqueous solutions. J Polym Eng 33:735-747

Filipkowska U, Jóźwiak T, Szymczyk P, KuczajowskaZadrożna M (2017) The use of active carbon immobilised on chitosan beads for rb5 and bv10 dye removal from aqueous solutions. Prog Chem Appl Chitin Deriv 22:14-26

Filipkowska U, Jóźwiak T, Bugajska P, Kuczajowska-Zadrożna M (2018) The influence of chitin amination on the effectiveness of RB5 and RY84 dye sorption. Prog Chem Appl Chitin Deriv 23:66-75

Hina K, Zou H, Qian W, Zuo D, Yi C (2018) Preparation and performance comparison of cellulose-based activated carbon fibres. Cellulose 25:607-617

Hospodarova V, Singovszka E, Stevulova N (2018) Characterization of cellulosic fibers by FTIR spectroscopy for their further implementation to building materials. Am J Anal Chem 9:303-310

Joshi Seema, Garg VK, Kataria Navish, Kadirvelu K (2019) Applications of $\mathrm{Fe}_{3} \mathrm{O}_{4} @ \mathrm{AC}$ nanoparticles for dye removal from simulated wastewater. Chemosphere 236:124280. https://doi.org/10.1016/j.chemosphere.2019.07.011

Jóźwiak T, Filipkowska U (2019) Sorption kinetics and isotherm studies of a Reactive Black 5 dye on chitosan hydrogel beads modified with various ionic and covalent cross-linking agents. J Environ Chem Eng (in press). https://doi.org/10.1016/j.jece.2019.103564

Jóźwiak T, Filipkowska U, Brym S, Kopeć L (2020) Use of aminated hulls of sunflower seeds for the removal of anionic dyes from aqueous solutions. Int $\mathrm{J}$ Environ Sci Technol 17:1211-1224. https://doi.org/10.1007/s13762019-02536-8 
Jóźwiak T, Filipkowska U, Szymczyk P, Zyśk M (2017) Effect of the form and deacetylation degree of chitosan sorbents on sorption effectiveness of Reactive Black 5 from aqueous solutions. Int J Biol Macromol 95:1169-1178

Kiefer J, Frank K, Zehentbauer FM, Schuchmann HP (2016) Infrared spectroscopy of bilberry extract water-in-oil emulsions: sensing the water-oil interface. Biosensors 6:1-11. https://doi.org/10.3390/bios6020013

Lindman B, Medronho B, Alves L, Costa C, Edlund H, Norgren $M$ (2017) The relevance of structural features of cellulose and its interactions to dissolution, regeneration, gelation and plasticization phenomena. Phys Chem Chem Phys 19:23704-23718

Lipatova IM, Makarova LI, Yusova AA (2018) Adsorption removal of anionic dyes from aqueous solutions by chitosan nanoparticles deposited on the fibrous carrier. Chemosphere 212:1155-1162

Mihułka M, Sójka-Ledakowicz J, Gajdzicki B, Machnowski W, Żyłła R, Lewartowska J, Grzywacz K, Strzelecka-Jastrząb E (2003) Technological characteristics of the textile industry in the European Union. Ministry of the Environment, Warsaw

Osler K, Twala N, Oluwasina OO, Daramola MO (2017) Synthesis and performance evaluation of chitosan/carbon nanotube (chitosan/MWCNT) composite adsorbent for post-combustion carbon dioxide capture. Energy Procedia 114:2330-2335

Oyelude EO, Awudza JAM, Twumasi SK (2017) Equilibrium, kinetic and thermodynamic study of removal of Eosin Yellow from aqueous solution using teak leaf litter powder. Sci Rep 7:1-10. https://doi.org/10.1038/s41598-01712424-1
Pan Y, Xie H, Liu H, Cai P, Xiao H (2019) Novel cellulose/montmorillonite mesoporous composite beads for dye removal in single and binary systems. Bioresour Technol 286:121366. https://doi.org/10.1016/j.biortech.2019. 121366

Thakur VK (2015) Cellulose-based graft copolymers: structure and chemistry. In: Singh SP, Soni B, Bajpai SK (eds) Chemically modified cotton fibers for antimicrobial applications. CRC Press, Boca Raton, pp 235-267

Toosi FS, Hosseiny M, Joghataei A, Toosi FS (2017) The application of $\mathrm{SiO}_{2}$ nanoparticles for anionic dye removal from aqueous solution. Arch Hyg Sci 6:136-144

Wawrzkiewicz M, Wiśniewska M, Gun'ko V (2017) Application of silica-alumina oxides of different compositions for removal of C.I. Reactive Black 5 dye from wastewaters. Adsorpt Sci Technol 35:448-457

Xiao X, Li T, Lu X, Feng X, Han X, Li W, Li Q, Yu HQ (2018) A simple method for assaying anaerobic biodegradation of dyes. Bioresour Technol 251:204-209

Zhang L, Wue W, Gu L (2019) Modification of hyperbranched hemicellulose polymer and its application in adsorbing acid dyes. Cellulose 26:5583-5601

Zhao B, Xiao W, Shang Y, Zhu H, Han R (2017) Adsorption of light green anionic dye using cationic surfactant-modified peanut husk in batch mode. Arab J Chem 10:3595-3602. https://doi.org/10.1016/j.arabjc.2014.03.010

Publisher's Note Springer Nature remains neutral with regard to jurisdictional claims in published maps and institutional affiliations. 